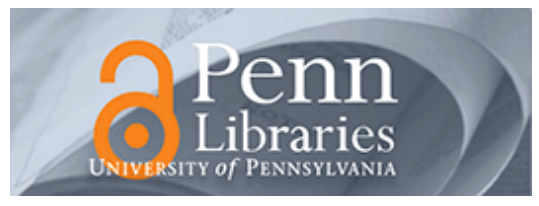

University of Pennsylvania

ScholarlyCommons

Finance Papers

Wharton Faculty Research

$11-2013$

\title{
Learning from My Success and from Others' Failure: Evidence from Minimally Invasive Cardiac Surgery
}

Diwas KC

Bradley R. Staats

Francesca Gino

Follow this and additional works at: https://repository.upenn.edu/fnce_papers

Part of the Business Administration, Management, and Operations Commons, and the Finance and Financial Management Commons

\section{Recommended Citation}

KC, D., Staats, B. R., \& Gino, F. (2013). Learning from My Success and from Others' Failure: Evidence from Minimally Invasive Cardiac Surgery. Management Science, 59 (11), 2435-2449. http://dx.doi.org/10.1287/ mnsc. 2013.1720

This paper is posted at ScholarlyCommons. https://repository.upenn.edu/fnce_papers/116

For more information, please contact repository@pobox.upenn.edu. 


\title{
Learning from My Success and from Others' Failure: Evidence from Minimally Invasive Cardiac Surgery
}

\author{
Abstract \\ Learning from past experience is central to an organization's adaptation and survival. A key dimension of \\ prior experience is whether an outcome was successful or unsuccessful. Although empirical studies have \\ investigated the effects of success and failure in organizational learning, to date, the phenomenon has \\ received little attention at the individual level. Drawing on attribution theory in psychology, we investigate \\ how individuals learn from their own past experiences with both failure and success and from the \\ experiences of others. For our empirical analyses, we use 10 years of data from 71 cardiothoracic \\ surgeons who completed more than 6,500 procedures using a new technology for cardiac surgery. We \\ find that individuals learn more from their own successes than from their own failures, but they learn \\ more from the failures of others than from others' successes. We also find that individuals' prior \\ successes and others' failures can help individuals overcome their inability to learn from their own \\ failures. Together, these findings offer both theoretical and practical insights into how individuals learn \\ directly from their prior experience and indirectly from the experiences of others.
}

\section{Keywords}

failure, healthcare, knowledge work, learning, quality, attribution theory

\section{Disciplines}

Business Administration, Management, and Operations | Finance and Financial Management 
H A R VAR D B U S I N E S S S C H O O L

Learning from My Success and From Others' Failure: Evidence from Minimally Invasive Cardiac Surgery

Diwas KC

Bradley R. Staats

Francesca Gino

\section{Working Paper}

12-065

July 19, 2012 


\title{
Learning from My Success and From Others' Failure: Evidence from Minimally Invasive Cardiac Surgery
}

\author{
Diwas KC* \\ Emory University \\ 1300 Clifton Road NE \\ Atlanta, GA 30322 \\ Tel: 404-727-1424 \\ Fax: 404-727-6313 \\ diwas_kc@bus.emory.edu \\ Bradley R. Staats \\ University of North Carolina at Chapel Hill \\ Campus Box 3490, McColl Building \\ Chapel Hill, NC 27599-3490 \\ Tel: 919-962-7343 \\ Fax: 919-962-6949 \\ bstaats@unc.edu \\ Francesca Gino \\ Harvard Business School \\ Harvard University, Baker Library \\ Boston, MA 02163 \\ Tel: 617.495.0875 \\ Fax: 617.496.4191 \\ fgino@hbs.edu
}

July 14, 2012

* Corresponding Author

\section{Acknowledgments}

We thank Mike Luca, Ella Miron-Spektor, Lamar Pierce, and Enno Siemsen for valuable comments on earlier drafts of the paper. We are grateful to Jesper Sørensen, the associate editor, and to the referees who provided constructive and developmental assistance throughout the review process. All errors remain our own. 


\title{
Learning from My Success and From Others’ Failure: Evidence from Minimally Invasive Cardiac Surgery
}

\begin{abstract}
Learning from past experience is central to an organization's adaptation and survival. A key dimension of prior experience is whether an outcome was successful or unsuccessful. While empirical studies have investigated the effects of success and failure in organizational learning, to date the phenomenon has received little attention at the individual level. Drawing on attribution theory in psychology, we investigate how individuals learn from their own past experiences with both failure and success and from the experiences of others. For our empirical analyses, we use ten years of data from 71 cardiothoracic surgeons who completed over 6,500 procedures using a new technology for cardiac surgery. We find that individuals learn more from their own successes than from their own failures but learn more from the failures of others than from others' successes. We also find that individuals' prior successes and others' failures can help individuals overcome their inability to learn from their own failures. Together, these findings offer both theoretical and practical insights into how individuals learn directly from their prior experience and indirectly from the experiences of others.
\end{abstract}

Key Words: Failure, Healthcare, Knowledge Work, Learning, Quality, Attribution theory

\section{Introduction}

Failure is simply the opportunity to begin again, this time more intelligently. - Henry Ford It's fine to celebrate success but it is more important to heed the lessons of failure. - Bill Gates

The importance of failure in the learning process is well recognized by conventional wisdom as well as by the academic literature (Lapré and Nembhard 2010; Edmondson 2011). Research on organizational learning has demonstrated that failure is central to both adaptation and change (Chuang and Baum 2003; Baum and Dahlin 2007; Kim and Miner 2007; Madsen and Desai 2010). Failure is considered beneficial to learning since it draws attention to potential or real problems, and it stimulates the search for new strategies or approaches rather than the reinforcement of existing ones (Baum and Dahlin 2007; Chuang and Baum 2003). Although insightful, to date, this literature has primarily focused on why organizations fail to learn and on what strategies they can develop to learn effectively from failure over time (Haunschild and Sullivan 2002; Haunschild and Rhee 2004; Madsen and Desai 2010). However, scholars and managers alike increasingly recognize that learning at the individual level is central to the understanding of organizational learning (Crossan, Lane and White 1999; Argote and Miron-Spektor 2011; Staats and Gino 2012). Despite its importance for organizational learning, the question of how individuals learn from failure, as compared to success, has received little empirical attention.

Drawing on attribution theory in psychology (Ross and Nisbett 1991; Gilbert and Malone 1995), 
in this paper we investigate how individuals learn from both failure and success. We focus not only on individuals' own past experiences, but also on how the experiences of others influence individuals' own learning (Levitt and March 1988; Huber 1991; Miner and Haunschild 1995). Whether an individual's past experience resulted in a success or a failure is an important predictor of future performance, because each type of experience may result in varied levels of willingness for the individual to engage in different improvement activities. Prior research argues that success leads to local search - that is, the refining of previous actions - while failure leads to non-local search, or more substantial deviation from prior choices (Audia and Goncalo 2007; Baum and Dahlin 2007; Lapré and Nembhard 2010). Through failure, an individual can learn what does not work and then develop and try a new approach to increase her likelihood of reaching a successful outcome in the future (Sitkin 1992; March and Simon 1993; Cannon and Edmondson 2005). This difference in how past experience is processed has led to theoretical work on the greater benefits that may arise from failure rather than success. While empirical work supports this view at the organizational level (Madsen and Desai 2010), the same may not be the case for individuals. Individuals, in fact, may interpret their prior experiences differently than do organizations.

While failure may be an important source of information for learning, we propose that individuals may not rely on it as much as they rely on success when evaluating their own prior experiences. We base this prediction on attribution theory, a psychological theory that suggests individuals tend to attribute their failures to external factors (thus not recognizing the role of their actions in such failures) and their successes to internal factors (e.g., their effort or ability) (Ross and Nisbett 1991; Gilbert and Malone 1995). One of the main assumptions of attribution theory is that people interpret their environment in a way that allows them to maintain a positive image of themselves (e.g., as competent and hard-working individuals, see Weiner 1974). As a result, people explain their successes and failures by attributing them to factors that will allow them to feel as good as possible about themselves. When individuals fail, they are likely to view their own performance deficit not as the result of personal actions or effort they exerted on the task, but rather as the result of situational factors beyond their control. So, they may not learn from their potential mistakes and may approach future tasks in ways that are similar to how they approached the same tasks in the past. In fact, when applied to motivation and learning, attribution theory suggests that a person's own attributions for success and failure determine how hard the person will work on the task or activity in the future (Weiner 1974). When attributions point to internal, controllable factors such as effort, they trigger greater motivation than those that point to external, uncontrollable factors such as luck (Bandura 1977). Thus, as a result of these biased attributions, individuals are likely to fail to improve as much from their own failures as they do from their own successes.

Prior research on individual learning found that people not only learn from their own experience, but also learn from the experiences of other individuals (e.g., Gino et al. 2010). Attribution theory 
suggests that the way people interpret success and failure will differ when they evaluate the actions of others as compared to their own actions. Namely, individuals tend to attribute the failures of others to internal factors (i.e., others' actions, effort, and abilities) and the successes of others to external factors (i.e., situational forces beyond their control, such as luck). We propose that individuals are more likely to learn from others' failures than from others' successes because individuals will be more likely to change their approach to learning and glean more knowledge from the former than from the latter. Therefore, by drawing on attribution theory, we examine individual performance as a result not only of an individual's own successes and failures, but also the successes and failures of others within the same organization.

While attribution theory suggests that individuals may learn less from their own failures than from their own successes, we wish to examine whether certain types of prior experience may help to counteract this effect. To investigate this question, we explore the potential complementary relationship between an individual's prior successful experience and the individual's prior failure experience. Prior successful experiences may change an individual's willingness and ability to recognize his or her own responsibility in a failure. Additionally, the experiences of others may improve the individual's ability to process knowledge from a personal failure. Thus, we also explore whether individual prior successful experience and the prior failure experience of others within the organization each interact with individual failure experience to increase the rate of learning.

We test our predictions using a unique dataset on 71 cardiothoracic surgeons who over ten years complete more than 6,500 procedures in a new process technology within healthcare: minimally invasive cardiac surgery (Friedrich, Bonatti and Dapunt 1997). The setting offers several benefits for our study. First, while our measure of failure, patient mortality, is absolute, the cause of failure is often relative given the complex individual (e.g., surgeon) and situational (e.g., patient severity) factors that lead to an outcome, thus providing a context where attributions can focus on either internal or external factors. Second, studies of learning in organizations often examine existing processes that have been completed many times before. Our dataset begins close to the rollout of the new procedure, thus allowing us to capture most surgeons' entire learning curves in our market.

By drawing on psychological research on attribution theory, the findings of this paper advance our understanding of individual learning and provide evidence consistent with our main hypotheses. First, we find that an individual's successful experience is more significantly related to current performance improvement than an individual's failure experience. Second, we find that the failure experience of others has a greater positive effect for an individual's current performance than does the successful experience of others. Third, we find that individual prior failures and individual prior successes have a complementary (i.e., positive) effect on individual current performance. In other words, the rate of learning from individual failure increases as an individual's volume of prior successful experience rises. 
Finally, we also find that individual prior failures and others' prior failures have a complementary (i.e., positive) effect on individual performance. That is, the rate of learning from individual failure increases as the volume of prior failure experienced by others within the same organization rises.

\section{Hypothesis Development}

As competition grows more global and knowledge based, learning in organizations is a key factor that can serve as a competitive differentiator (Stata 1989; Teece, Pisano and Shuen 1997; Drucker 1999). A large body of research has explored how and when different entities learn (Argote 1999; Lapré and Nembhard 2010; Lapré 2011). Prior research notes that learning can occur at various levels: individual (Newell and Rosenbloom 1981; Narayanan, Balasubramanian and Swaminathan 2009; Staats and Gino 2012), team (Pisano, Bohmer and Edmondson 2001; Reagans, Argote and Brooks 2005), and organizational (Argote, Beckman and Epple 1990; Lapré and van Wassenhove 2001). In addition, learning can occur not only from one's own actions (direct experience) but also from the experiences of others (indirect experience) (Levitt and March 1988; Huber 1991; Miner and Haunschild 1995). Empirical work supports this claim, finding that knowledge can be transferred, in part, across and within organizations (Argote et al. 1990; Darr, Argote and Epple 1995; Ingram and Roberts 2000). However, while this body of research finds evidence for individual learning from both direct and indirect experience, until recently, it did not examine differential learning based on a successful or failed outcome.

Traditionally, the majority of studies of learning in organizations either did not distinguish between success and failure or implicitly focused on learning from successful past experience (Argote 1999; Lapré and Nembhard 2010). However, more recently, empirical work on learning from failure finds that organizations do engage in it (Haunschild and Sullivan 2002; Chuang and Baum 2003; Haunschild and Rhee 2004). At the organizational level, research has shown that organizations learn from both the failures and near-failures of other firms (Kim and Miner 2007) and that such learning positively impacts their survival rates (Ingram and Baum 1997; Chuang and Baum 2003). Previous studies also compared the learning gained from success to the learning gained from failure at the organizational level and found mixed results (Lapré and Nembhard 2010). In some cases, learning from success had a stronger effect than learning from failure (Baum and Dahlin 2007), while in others, the effects of learning from failure dominated (Li and Rajagopalan 1997; Madsen and Desai 2010).

Learning in organizations refers to the improvement of performance "through better knowledge and understanding" (Edmondson 2002: 128). While studies of learning in organizations often focus on the cumulative volume of the organization as a means of measuring an organization's knowledge, it is through the actions and interactions of individuals that such knowledge is captured, adapted, and applied (Argote and Ingram 2000; Staats 2012). As work grows more specialized and is divided into smaller 
tasks, the role of individuals in organizational learning increases in importance (Argote and MironSpektor 2011; Malone, Laubacher and Johns 2011; Chan, Li and Pierce 2012; Staats and Gino 2012). By focusing on individuals, we can gain a more nuanced understanding of how success and failure lead to either performance improvement or performance degradation in organizations.

As noted by Madsen and Desai (2010), prior success and prior failure may have differential effects on both the motivation to learn as well as the knowledge acquired to enable learning. With respect to the former, as individuals complete a task, they have a view of satisfactory performance, often referred to as a goal or an aspiration (Locke and Bryan 1967; Greve 1998). If performance meets or exceeds the goal, then they are likely to continue on the same course of action. On the other hand, if performance falls below the standard ("failure"), they may be more motivated to learn and identify the cause of the failure (Cyert and March 1963; Locke et al. 1981; March and Simon 1993). The effects of success may be even more insidious for motivation since success increases the likelihood of overconfidence, which may further remove the motivation to learn (Moore and Healy 2008; Gino and Pisano 2011).

Success and failure may also affect the knowledge that is (or is not) acquired from experience. The behavioral theory of the firm posits that individuals in organizations respond with different actions after success and failure (Cyert and March 1963; March and Simon 1993; Gavetti, Levinthal and Ocasio 2007). After a success, individuals are likely to engage in local search, contingent on the fact that they engage in any additional search. Because the prior experience was successful, an individual is likely to conclude that she has the appropriate knowledge at hand and understands the situation. Therefore, rather than revisiting her existing assumptions, beliefs, and schemas, she is likely to refine them (Piaget 1963; Weick 1984; March 1991; Lant 1992).

On the other hand, after failure, individual decision makers are likely to engage in a different kind of search. First, after failure, individuals may look for information in different places than they otherwise would. This could involve both increased breadth of search (e.g., books or new experts) as well as increased depth of search (more time with each source). Second, failure may change the way people process information. Failure reveals that existing ways of operating are no longer sufficient or appropriate and that prior assumptions are incorrect (Sitkin 1992). Thus, individuals may be more willing to engage in reflection that can improve learning (Argyris and Schön 1978). Further, by opening oneself to the idea that the prior schema was flawed, an individual may consult information previously thought irrelevant (or at least unnecessary) and in doing so create new and potentially improved beliefs that will positively affect future performance (Piaget 1963).

While the prior arguments point toward a stronger effect for learning from failure than from success, attribution theory suggests that at the individual level, learning from failure may not be quite so straightforward. Research in psychology finds that people strive to understand their own prior experiences 
as well as the prior experiences of others by making attributions about events (Heider 1958; Wong and Weiner 1981). For many decades, social psychologists have investigated how people make such attributions when they form judgments of others and of themselves (Lewin 1931; Katz and Kahn 1966). For example, suppose that an individual reads about a student's performance on a test and then judges the person's knowledge and ability to decide whether to admit him to a Quizbowl team (Moore et al. 2010). In this case, the individual is making inferences based on knowledge provided to her, such as the student's answers on the test and the average score of other students who took the test. These inferences require accurate attributions of the cause-and-effect relationships that led to the outcome. For instance, a student may have received a low score on the test after correctly answering only two questions out of ten. However, before concluding that the student is not very knowledgeable, the individual making the judgment should consider the difficulty of the test and how it may have impacted the student's ability to answer the questions. An individual's outcomes are jointly determined by both his choices and the situation in which he acts, yet numerous studies indicate that people often do not weight these factors appropriately (Jones and Davis 1965; Kelley 1967). For example, while low lighting on a basketball court increases the difficulty of making a shot, one study found that shooters randomly assigned to a less-welllit court were judged less capable than shooters assigned to a well-lit court (Ross, Amabile and Steinmetz 1977). In a more extreme version of the same phenomenon, when an individual read aloud a randomly assigned speech that did not necessarily reflect her opinions on a given topic (e.g., pro-life vs. prochoice), listeners tended to attribute the views expressed to the reader, though they were told the speech had been randomly assigned to the reader (Jones and Harris 1967). Going back to our initial example, even when people are provided with full information about a situation (e.g., average score on the test and standard deviation), they still make biased attributions of the student's ability (Moore et al. 2010).

Furthermore, psychological research on attribution finds that people incorrectly weight the individual and situational effects on behavior in systematic ways based on whether they are evaluating themselves or someone else (Heider 1958). In particular, when individuals assess their own performance, they are likely to overweight situational forces and underweight individual forces, but when they assess others' performance, they do just the opposite: they tend to underweight situational forces and overweight individual ones (Gilbert and Malone 1995). This phenomenon is so robust that it has been named the "fundamental attribution error" (Ross 1977).

While prior research establishes that an individual makes different attributions based on whether she or another person is performing a task and whether the outcome is a success or a failure, the question we address in this paper is how attributions affect subsequent performance improvement and learning. Research suggests that learning occurs through repeated cycles of action and reflection (Piaget 1963; Argyris and Schön 1978). The attributions that a person makes will affect her reflection process, or lack 
thereof. Early attribution research in psychology examined how people's different attributions affected their subsequent effort and motivation, and identified four categories of attributions: effort, ability, task difficulty, and luck (Weiner 1974). Ability and effort are perceived as causes originating within the individual (internal causes); task difficulty and luck are perceived as causes outside the individual (external causes). One important dimension on which internal causes differ is their degree of controllability: while effort is controllable, ability often is not, as people believe it is innate and cannot be changed (Weiner 1979; 1995). The attributions people make about the causes of their successes and failures influence motivation and effort in subsequent tasks (and thus learning) but to a different degree depending on the type of attributions made (Weiner 1974). In achievement contexts, where individuals are interested in reaching high levels of performance (for instance, based on given goals they set for themselves), people tend to attribute their own success to their effort and ability. Since they have control over their own effort and actions, these attributions motivate them to exert effort in subsequent tasks so that they can continue improving and learning (Weiner 2001). When interpreting their own failures, instead, individuals tend to make external attributions, pointing to factors that are outside of their direct control (such as luck). As a result, their motivation to exert effort on the same task in the future is reduced (Weiner 2001). In fact, believing that factors that one can control directly lead to success promotes greater effort and learning, which may help people avoid future failures (Bandura 1977). Thus, even though an individual failure experience may contain valuable knowledge, without subsequent effort to reflect upon that experience, the potential learning will remain untapped. Further, since individuals tend to seek knowledge about themselves in ways designed to yield flattering results (Sedikides 1993), even if someone were to engage in reflection after failing, he might seek knowledge to explain away the failure. In its most extreme form, failure could lead to worse performance because, in an effort to enhance his own self-image, an individual could glean the wrong, misleading lessons from the prior experience.

The relationship between attributions and subsequent effort is also likely to affect learning from the experience of others. When another person is successful, our focal individual is likely to make an external or situational attribution. In attributing the success to factors such as luck or task difficulty, an individual's willingness to exert additional effort in order to learn may be lower because these factors are outside one's own control. On the other hand, when evaluating the failures of others, there is an increased possibility for learning. Since an individual is likely to believe that the other person is responsible for the failure due to his effort and actions, this creates the possibility that an individual may exert additional effort in order to understand what went wrong. Self-enhancement motives (Taylor and Brown 1988) may also play a role in the way people interpret others' failures. Since people want to see themselves as capable and successful, and look for information consistent with such self-views (Sedikides 1993; Dunning 1999), they are likely to pay attention to others' failures and attempt to understand them so that 
they can avoid failing in the same ways. Thus, an individual's motivation to self-enhance is likely to raise the salience of others' failures so that she can be assured that she will not make the same mistakes and suffer from a negative evaluation as a result. Given that failure may yield valuable knowledge, this suggests not only that an individual may exert additional effort after another person's failure - leading to increased reflection - but that there may be additional knowledge to reflect upon, meaning that, in practice, others' failures may generate the most learning of all for an individual.

Together, these arguments lead to two hypotheses about how individuals learn directly from their own prior experience and indirectly from the experience of others. First, we predict that individuals will learn more from their own success as compared to their own failure. Second, we predict that individuals will learn more from the failures of others than from the successes of others. Thus, we hypothesize:

HYPOTHESIS 1: $\quad$ The prior successes of an individual have a greater effect on the individual's current performance than do the individuals' prior failures.

HYPOTHESIS 2: $\quad$ The prior failures of other workers have a greater effect on an individual's current performance than do the prior successes of others.

As our first hypothesis suggests, attribution theory leads us to predict that individuals will learn less from their own failures than from their own successes. What conditions can help to counteract this effect and, in so doing, increase learning after an individual's own failure? To address this question, we first consider the role of an individual's prior successes. We suggest that past experience with individual success may create a foundation for an individual to learn more from a recent individual failure. In general, one of the reasons people tend to attribute their own failures to external rather than internal factors is that failures constitute a threat to their abilities and positive self-concept. When people have had a successful experience, this perceived threat is likely to disappear. As a result, people are less likely to be self-serving in their attributions and thus less likely to attribute failure to external factors. Consistent with these arguments, Campbell and Sedikides (1999) found that when people experience little self-threat, they are less likely to make self-serving attributions. This lowered need for self-serving attributions may help an individual exert effort after an individual failure in order to attempt to learn.

In addition to reducing the possibility that an individual will make self-serving attributions, past successful experience may also provide the individual with information that helps her better interpret a failure. As an individual gains successful experience, she begins to understand how to complete a task and how the different components of the task fit together (Bohn 2005; Bohn and Lapré 2011). This underlying causal knowledge may increase the learning rate from individual failure experience. First, when an 
individual understands a given context, she is more likely to recognize a failure for what it is - a gap in existing knowledge or practice. When she has a better comprehension of how things work, it will be more difficult for her to blame the outcome on the situation (Moore et al. 2010). Not only may prior successful experience increase the likelihood of recognizing a failure as an individual responsibility, thus creating the motivation to improve, but prior successful experience may also help the individual use such knowledge more effectively. After a failure, an individual may look for information in different places. Prior successful experience can serve as a guide for possible places to look or not look (Fleming and Sorenson 2004; Blume and Franco 2007). Also, when an individual engages in reflection, prior successful experience may prove useful, as prior successful experience provides knowledge on what has worked in the past. Combined with the knowledge gained through failure, an individual can work through the process of creating and then testing new hypotheses. Finally, research on associative learning offers evidence as to why prior success may help individuals respond to failure (Sternberg 2003; Kim, Kim and Miner 2009). When failure occurs after a series of successes, it marks a salient deviation that may be noticed precisely because of its salience (Taylor and Fiske 1978). Further, the combination of failure and success experiences creates the ability to compare knowledge gained in each situation, reducing uncertainty in the causal relationships in each case (Morris and Moore 2000). Consistent with this argument, at the organization level, Kim et al. (2009) find evidence for a beneficial interaction effect between success and a near-failure experience on firm survival. Together, this reasoning leads us to hypothesize:

HYPOTHESIS 3: An individual's prior failures and prior successes have a complementary (i.e., positive interaction) effect on the individual's current performance.

Finally, we consider how the failures of others may affect an individual's ability to learn from his or her own failures. Research has found that salient, distinctive, and visible information facilitates the attribution process since such information tends to easily capture attention (Heider 1958; Taylor and Fiske 1978). Since they are negative events, failures are more vivid and more salient than successes (Baumeister et al. 2001). Thus, others' failures are likely to influence one's own learning. Specifically, we propose that the failures of others are likely to improve an individual's ability to learn from personal failure for two main reasons. First, others' failures change the dynamics for how people internalize their own failures (Wood and Bandura 1989). In fact, observing others fail can trigger a process of reflection that allows people to identify new ways of approaching problems. Individuals are likely to attribute others' failures to a lack of effort or ability (internal causes). They will want to avoid failing on the same task in the future because failure threatens their sense of competence. When people experience such 
threats, they are motivated to take actions aimed at maintaining a positive self-image; thus, seeing others fail is likely to increase their willingness to search for ways to improve in order to avoid such failures. When she sees others fail, and interprets those failures to others' actions and effort (namely, controllable factors), then she may be more willing to accept responsibility for her own personal failure and thus create the possibility of learning from it. Thus, when failure is a possibility, individuals become willing to own up to their own actions rather than blaming the situation.

The second reason that others' failures may improve individual learning from one's own failure is that the failure of others creates the opportunity for a first-mover advantage. ${ }^{1}$ If individual failure leads to a decreased motivation to learn, then observing others fail may overcome this motivation problem. In particular, when others fail, then an individual has the opportunity to shine by solving a problem. Given the potential benefits of others' failures for both an individual's motivation and her problem solving and information processing, we hypothesize:

HYPOTHESIS 4: An individual's prior failures and the prior failures of others have a complementary (i.e., positive interaction) effect on the individual's current performance.

\section{Setting, Data and Empirical Strategy}

\subsection{Setting}

Cardiac care is a high-volume and high-revenue service sector, accounting for one-third of the entire patient volume in the United States and over a third of all Medicare spending (AHA 2008). In particular, coronary artery disease, a clinical condition in which plaque builds up in the arteries that supply oxygenated blood to the heart muscle (or the myocardium), affects millions of individuals. Left untreated, this condition can lead to adverse physiological function, angina (chest discomfort), and heart attacks. Congestive artery disease is the leading cause of death for men and women in the United States (AHA 2008).

One of the most common clinical solutions for dealing with congestive artery disease is to bypass the blocked vessels using another donor vessel. This procedure, known as coronary artery bypass grafting $(\mathrm{CABG})$, was developed in the late sixties and has helped millions of patients since then. CABG is an invasive procedure in which the heart is stopped while the cardiothoracic surgeon performs the grafting procedure. Once the vessels have been sutured into place, the heart is then restarted. The process of

\footnotetext{
${ }^{1}$ We thank an anonymous reviewer for this suggestion.
} 
stopping and restarting the heart has been shown to adversely impact patient health. CABG Patients have been shown to have an elevated risk of depression and adverse physiological functioning in addition to increased risk of neurological complications such as stroke (Roach et al. 1996; Puskas et al. 1998).

In the late 1990s, an innovative new CABG procedure known as off-pump (or minimally invasive) $\mathrm{CABG}$ was developed that allowed surgeons to operate on the heart without having to stop and restart it. This procedure called for process-level changes (in particular, having to handle and make incisions on the beating heart) and increased surgical skill and dexterity. Specifically, surgeons must extensively study and learn this new procedure before practicing it.

In this paper, we examine the learning curve for surgeons who perform this class of minimally invasive cardiac procedures. We chose this setting for several reasons. First, learning is a key driver of surgeon success. Specifically, we are able to examine clinical outcomes (success or failure) based on the cumulative volume of minimally invasive procedures performed by the surgeon. Second, there exists a significant body of medical literature that has examined the clinical drivers of success in cardiac surgery. We can draw on this prior work to generate more accurate "risk-adjusted" measures of outcomes. We also draw on a growing management literature (e.g., Pisano et al. 2001; Huckman 2003; KC and Staats 2012) that has examined CABG. Third, we are able to collect data from early in the deployment of the CABG process, when the greatest learning likely occurred. The most significant of these minimally invasive procedures was introduced in 1998 (Gardner 2001). We observe individual learning for every month beginning in October 1999 for a period of 120 months; therefore, our data set is comprehensive enough to accurately trace the learning curves for the surgeons in our sample. ${ }^{2}$

\subsection{Data}

Our data set includes information on all of the minimally invasive cardiac procedures performed in Massachusetts from October 1999 to September 2009. This includes information about 6,570 minimally invasive procedures performed by 71 cardiac surgeons over the 10 -year period. Fifty-four of the patient encounters had incomplete observations and missing covariates, leaving a total of 6,516 observations that we use in our analysis. Our outcome variable or quality measure is the in-hospital postoperative mortality rate, which is the most commonly used metric for benchmarking the performance of surgeons and institutions that perform cardiac surgery. Several patient-level factors have been shown to impact surgical outcomes, such as demographic variables, including age, gender, and race. Pre-existing risk factors, such as incidence of diabetes and poorly functioning bodily organs, are also known to affect outcomes (Nashef et al. 2002). To account for these risks, we include these patient-level factors in our analysis. We find that the average age of a patient undergoing a minimally invasive cardiac procedure is about 67 years

\footnotetext{
${ }^{2}$ As noted by Lapré and Tsikriktsis (2006), studies that examine learning curves long after production has started are not biased. They are, however, estimating learning rates for a latter part of the learning curve.
} 
(standard deviation 11.2). The vast majority of patients have at least one significant accompanying clinical risk (e.g., cerebrovascular disease, neurologic or pulmonary risk, diabetes).

Our analysis focuses on estimating learning from failure and successful experience. Since individual surgeon-level heterogeneity, such as reputation and training, could impact performance, we include the encrypted surgeon identifier and the unique patient-surgeon pairs in our analysis. Specifically, we observe the patient controls, the specific surgeon who operated on the patients, the level of experience the surgeons had accumulated by the time they performed the surgery, and the outcome of the surgery.

In general, accurately estimating an individual worker's learning curve is challenging for two reasons. First, perfecting a highly specialized task like a minimally invasive surgical procedure takes years. Since learning occurs over a long time horizon, an accurate estimation of individual learning curves calls for a long panel of observations. Second, data collection ideally should start at the beginning of the learning curve, when the surgeon first starts to perform the procedure, which is when the greatest learning is likely to occur. Our comprehensive data set allows us to overcome both of these challenges: we not only observe surgeon learning over a lengthy ten-year period but also begin the observations close to the introduction of the procedure into the marketplace. Because we include the surgeon identifier in our analysis, our estimates examine the effect of cumulative volume at the individual surgeon level. We also observe the hospitals where each surgeon practices. This allows us to generate a list of surgeons who practiced at the same hospital and estimate the effect of failures and successes of all other surgeons from that hospital. This is our measure of others' failures and successes, respectively. Our empirical analysis also includes the hospital fixed effect, which accounts for effects of group membership on outcomes.

\subsection{Empirical Strategy}

In the discussions below, the subscript $s$ denotes the surgeon, $i$ denotes the patient, and $t$ denotes time. The key outcome variable in our analyses, $M O R T_{\text {ist, }}$, equals 1 if patient $i$, who underwent a minimally invasive cardiac procedure performed by surgeon $s$ at time $t$, died, and 0 otherwise. Multivariate logistic regression is widely used to model such binary outcomes in cardiac surgery (Nashef et al. 2002; KC, Terwiesch and Horak 2009) and in the literature on operational productivity and quality of care (Huckman and Pisano 2006; KC and Terwiesch 2009; KC and Staats 2012). We use the vector $\mathrm{X}_{\mathrm{it}}$ to denote patient-level covariates that are known to impact outcomes. In particular, $\mathrm{X}_{\mathrm{it}}$ includes patient demographic factors as well as clinical risk factors. The vector $T_{t}$ includes temporal factors, including the month and year of a procedure as well as its day of the week.

Our primary explanatory variables are the cumulative volume of minimally invasive procedures performed by surgeon $s$ at time $t$. Specifically, we define the cumulative experience as follows: 
$E_{F A I L_{s t}}=\sum_{t^{\prime}=t_{0}}^{t} \sum_{i} I_{i s t^{\prime}} \times F A I L_{i t^{\prime}}$ and $E_{S U C C_{s t}}=\sum_{t^{\prime}=t_{0}}^{t} \sum_{i} I_{i s t^{\prime}} \times\left(1-F A I L_{i t^{\prime}}\right)$

where $I_{i s t^{\prime}}=1$ if surgeon s performed a minimally invasive cardiac procedure on patient $i$ at time $t^{\prime}$ between the beginning of our study period $\left(t_{0}\right)$ and time $t$, and 0 otherwise. Also, $S U C C_{i t}=1$ if the minimally invasive procedure performed on patient $i$ at time $t$ was successful, and $F A I L_{i t^{\prime}}=1$ otherwise. $E_{\text {SUCCSt }}$ and $E_{\text {FAILst }}$ are thus the cumulative volumes of successes and failures for surgeon $s$ at time $t$, respectively. Similarly, we define $E_{\text {FAIL_OTHERSst }}$ and $E_{\text {SUCC_OTHERSSt }}$ to be the cumulative failures and successes of the other cardiac surgeons who work in the same hospital as surgeon $s$.

To explore the impact of individual failures and successes, and those of others, we employ the following empirical specification. ${ }^{3}$

$$
\begin{aligned}
\ln \left[\frac{\operatorname{Pr}\left(M O R T_{i s t}=1 \mid X_{i t}\right)}{1-\operatorname{Pr}\left(M O R T_{i s t}=1 \mid X_{i t}\right)}\right] \\
=\alpha+X_{i t} \beta_{0}+S_{s}+H_{h}+T_{t}+\beta_{1} E_{\text {SUCC }}+\beta_{2} E_{\text {FAIL }}+\beta_{3} E_{\text {SUCC_OTHERS }} \text { st } \\
+\beta_{4} E_{\text {FAIL_OTHERS }_{\text {st }}}+\varepsilon_{\text {ist }}
\end{aligned}
$$

$S_{s}$ denotes the "surgeon fixed effect." This allows us to account for unobserved surgeon-level heterogeneity, including reputation, training, and medical background. Because some surgeons practice at more than one hospital, we also include the hospital fixed effect, $H_{h}$, which allows us to account for unobserved hospital-level heterogeneity. The vector $T_{t}$ includes temporal factors, including the time period when the surgery was performed (specifically, a unique identifier for the month and year of a procedure) as well as its day of the week. The time fixed effect allows us to account for any changes in the underlying technology over time. Our estimators of concern are $\beta_{1}$ and $\beta_{2}$, which capture the effect of an additional unit of experience (i.e., one more single cardiac procedure) from a success and failure for surgeon $s$ in reducing the likelihood of risk-adjusted mortality for patient $i$ at time $t . \varepsilon_{\text {isht }}$ is the random error term. Likewise, $\beta_{3}$ and $\beta_{4}$ capture the effect of learning from the success or failure of a coworker in reducing the likelihood of risk-adjusted mortality for patient $i$ at time $t$. A larger negative value for $\beta_{1}$ as compared to $\beta_{2}$ would provide support for hypothesis H1. Similarly, a larger negative value for $\beta_{4}$ as compared to $\beta_{3}$ would provide support for hypothesis $\mathrm{H} 2$. We note that the above specification follows a long line of research in cardiac risk stratification that link patient risk variables to outcomes using a logistic regression (see also, Parsonnet, Dean and Bernstein 1989; Higgins et al. 1992; Nashef et al.

\footnotetext{
${ }^{3}$ We use counts of our experience variables, rather than their logs for two reasons. First, the log-linear learning curve model is derived from theory, and supported empirically while the log-log learning curve model is just from empirical results (Levy 1965; Lapré, Mukherjee and Wassenhove 2000). Second, if experience has been gained prior to the start of the dataset then the log-log learning curve model will yield biased coefficients (Lapré and Tsikriktsis 2006). Some surgeons have experience prior to the start of our dataset and so a log-linear model is preferred.
} 
2002). We augment this prior work to examine the effect of cumulative individual failures and successes as well as those of others.

We next consider the interaction effects that we hypothesized earlier: the moderating effect of individual success on individual failures, as well as the moderating effect of the failures of others on the failures of individuals. The following empirical specification includes these interaction terms:

$$
\begin{aligned}
& \ln \left[\frac{\operatorname{Pr}\left(M O R T_{i s t}=1 \mid X_{i t}\right)}{1-\operatorname{Pr}\left(M O R T_{i s t}=1 \mid X_{i t}\right)}\right] \\
& =\alpha+X_{i t} \beta_{0}+S_{S}+H_{h}+T_{t}+\beta_{1} E_{\text {SUCC }}+\beta_{2} E_{\text {FAIL }}+\beta_{3} E_{\text {SUCC_OTHERS }} \\
& +\beta_{4} E_{\text {FAIL_OTHERS }_{\text {st }}}+\gamma_{1} E_{\text {SUCC }} \times E_{\text {FAIL }}+\gamma_{2} E_{\text {FAIL } s t} \times E_{\text {FAIL_OTHERS }_{s t}}+\varepsilon_{\text {ist }}
\end{aligned}
$$

$\gamma_{1}$ captures the interaction effect of individual successes and failures. A negative value for $\gamma_{1}$ would provide support for hypothesis H3. Similarly, $\gamma_{2}$ captures the effect of synergy (or lack thereof) between individual failures and the failures of others. A negative value would provide support for hypothesis $\mathrm{H} 4$.

Finally, for completeness, we use the empirical specification reported above, but include the interaction effect of individual and others' successes: $\gamma_{3} E_{\text {SUCCSt }}$ x $E_{\text {SUCC_OTHERSst }}$ Attribution theory does not lead to a particular prediction for this coefficient. In this model, $\gamma_{3}$ would capture the effect of any synergy between individual successes and others' successes. If individuals are more likely to learn from collective successes, we would find a negative coefficient for the interaction $\left(\gamma_{3}<0\right)$; if the collective successes of others do not have such synergistic effects, then we would find a non-significant effect.

\section{Results}

Our first hypothesis predicted that an individual's prior success would have a greater positive effect on the individual's performance than her prior failure would. Note that as our dependent variable is patient mortality, a negative coefficient is related to lower predicted mortality and therefore to positive performance. To test our first hypothesis, we examined the impact of one's own prior successes and failures on individual learning. As shown in Table 2, we find that individual failure does not lead to an improvement in surgical outcomes, as demonstrated by the positive and statistically significant coefficient of cumulative volume of minimally invasive surgical procedures (coefficient $=0.1709, p<0.05$ ). This corresponds to a decline in surgical performance by $76 \%$ for a standard deviation increase in the number of unsuccessful procedures for the surgeon. By contrast, individual failure is associated with improved surgical outcomes, as demonstrated by the negative and statistically significant effect for individual surgeon related experience (coefficient $=-0.00727, p<0.05$ ). This corresponds to an improvement in surgical outcome by a factor of $46 \%$ for a standard deviation increase in the number of successful 
procedures for the surgeon. The month and year fixed effects capture the effect of temporal improvements (e.g., better technology) during the period of study. Therefore, our individual surgeon estimates are obtained from cumulative experience above and beyond these temporal factors. The patient-level controls, where statistically significant, all have the expected signs. The coefficients for the effects of individual prior successes and individual prior failures are statistically different; a Wald test rejected the null hypothesis that the coefficients for the impact of failure and success are equal $(p=0.02)$. This provides support for the hypothesis that individual prior success has a greater positive effect on performance than does individual prior failure. On balance, however, increased experience does have a beneficial impact on outcomes. Based on an alternative empirical specification, where we examine the impact of cumulative experience (regardless of outcome) on future outcomes, we find (Table A-1) the estimate of cumulative volume to be $-0.00217(\mathrm{p}<0.10)$. This corresponds to an improvement in surgical outcomes by a factor of $17.3 \%$ for a standard deviation increase in the volume of overall experience.

As a test of robustness for the effect of learning from failures and successes, we include a specification that includes quadratic terms for self-failure and self-success (Table A-II). We find that the quadratic term for failures is positive and the quadratic term for success is negative. The coefficients on the quadratic terms are not large enough to produce U-shaped effects within the range of the data. However, they do suggest an attenuation of the effects of individual failures and successes over time. This result is different from that of Reagans et al. (2005), who find that performance first worsens with individual experience before improving. We note that Reagans et al. (2005) examine total experience (not success/failure) as well as inexperienced team members (residents or fellows). The surgeons in minimally invasive CABG are all board certified. An interesting extension of our work would be to examine a setting with individuals new to the field in order to study whether they are more or less prone to the effects we identify than those with more experience.

Our second hypothesis predicted that the prior failures of other workers would have a greater effect on an individual's performance than the prior successes of others would. We find that the failures of others (coefficient $=-0.0354, p<0.10$ ) have a significant beneficial effect in improving outcomes of individual surgeons. This corresponds to an improvement in surgical outcomes by a factor of $37.5 \%$ for a standard deviation increase in the failures of others. To compare the magnitude of these two effects on individual learning, we tested the null hypothesis that the coefficient for the effect of a prior failure of another worker is no different from the coefficient that captures the effect of a prior success of another worker. A Wald test rejected this null hypothesis $(p=0.08)$, leading to support for Hypothesis 2 .

Next, we examine our third hypothesis, which predicted that an individual's prior failures and prior successes would have a positive, complementary effect on individual performance. To test this hypothesis, in Table 3 (Model 1) we include the interaction effects between individual successes and 
failures. As predicted, we find that with each additional success, a failure offers greater opportunity to learn (coefficient $=-0.00189, p<.01$ ). Finally, we consider the interaction effect of individual failures and the failures of others to test our last hypothesis, which predicted that an individual's prior failures and the prior failures of others would have a positive, complementary effect on the individual's performance. Consistent with this hypothesis, we find (Model 2) that individual failures and the failures of others interact to have a beneficial learning experience (estimate $=-0.00699, p<0.01$ ).

Finally, for completeness, we also consider the interaction effect of individual successes and the successes of others even though we did not develop a specific hypothesis about this interaction. As shown in Model 4 of Table 3 (and in Model 3 without the other interactions), we do not find a statistically significant effect for this interaction term. Thus, it appears that an individual's prior successes and the prior successes of others do not have a statistically significant effect on one's own learning.

To rule out the possibility of patient selection as a possible driver of our results, we examined the correlation between patient preoperative risk and the failures of individual surgeons. This allows us to examine whether surgeons that fail operate on patients with greater risk factors. The preoperative risk was obtained by using the patient and procedural risk factors to predict the mortality rate. We find a lack of statistically significant correlation between the preoperative mortality risk and the previous failures for a given surgeon $(p=0.419)$, which rules out the possibility of a statistically significant effect of patient selection or matching on observable factors. As an additional check of robustness, we estimate the cumulative successes and failures of surgeons at other hospitals. We then include these newly constructed measures in our empirical specification. We find that failures and successes at other hospitals do not have a statistically significant effect on a surgeon's learning. This rules out the possibility of other industry- or technology-related confounders for our estimates.

\section{Discussion and Conclusion}

\subsection{Discussion of Results}

Prior research on organizational learning has explored both success and failure (Chuang and Baum 2003; Baum and Dahlin 2007; Madsen and Desai 2010), yet how individuals learn is likely different from how organizations learn. In this paper, we examined how individuals learn directly from their own past experience and indirectly from the past experience of others for both success and failure. We theorize and find evidence for a paradox of failure: individuals learn from the failures of others, but not from their own failures. Our empirical results add to existing research on individual learning in organizations and open up new questions that future research can investigate. First, we find that not only do individuals learn more from their own successful experiences than they do from their own failure experiences, but their performance worsens after failure. While our empirical design does not permit us to identify the 
mechanisms that drive this result, our underlying theory offers reasons for it. Attribution theory suggests that when individuals fail, they may be less likely to put forth effort in the future on the same tasks because they tend to attribute that failure to external circumstances beyond their control, such as luck (Weiner 1974). However, assuming that the outcome was not just a matter of external circumstances, but instead a joint function of both internal and external factors, then failure at least in part signals that something has gone wrong. If an individual does not put forth effort to learn what has gone wrong, then he may continue using the incorrect strategy going forward and commit even further to the existing solution strategy, even if it is flawed (Staw 1981).

A second question arising from our results is how they compare with existing studies of success and failure at the organization-level of analysis. Some prior studies have shown that learning from success has a stronger effect than learning from failure (Baum and Dahlin 2007), while others have demonstrated the opposite: namely, that learning from failure has a stronger effect than learning from success ( $\mathrm{Li}$ and Rajagopalan 1997; Madsen and Desai 2010). Though we cannot answer the question conclusively, our study offers some insight on these seemingly inconsistent findings. In particular, our results show that both performance improvement and performance degradation occur within the same organization (a hospital) in response to an individual's failure. While the focal individual does not learn from his or her mistake, others in the organization appear to do so.

In order to understand the effects of individual actions on organizational learning, scholars must be careful not to anthropomorphize the organization as they develop and test their theories. In other words, it is difficult to attribute organizational learning to a single individual's action, because both the focal individual and others in the organization observe and respond to events taking place within it. This is consistent with existing research highlighting that organizations can be thought of as interpretation systems that attempt to decipher what has occurred (Daft and Weick 1984; Levitt and March 1988). One implication of this view is that, in order to understand the effect of success or failure on a firm, it may be necessary to know who the actors were both before and after an event occurs. For example, if managers in the railroad context of Baum and Dahlin (2007) kept their jobs after a failure occurred, then possible learning from the failure might remain uncaptured. This would not only prevent organizational learning but also could lead to a worsening of performance, as the researchers find. On the other hand, if the unsuccessful project managers in Madsen and Desai's (2010) orbital launch context were fired after experiencing failure, this might translate to successful organizational learning, as the other managers could observe and learn from the failure. Madsen and Desai (2010) also find that, counter to the idea of small losses (Sitkin 1992), bigger failures lead to more organizational learning. This finding is consistent with the managerial turnover hypothesis, as larger failures might increase the likelihood of a manager being fired, which might then lead to greater organizational learning. 
While these are only speculations, they highlight the many factors that may determine how an organization made up of individuals may learn from success and failure. Further insight could be gained by studying the organizational response to failure in general as well as specific responses, such as those of central actors in the organization. The behavioral theory of the firm explicitly details how organizational processes are compromises between rival factions within an organization (March and Simon 1993). Given that fact, it is important to understand when a failure may lead to a shift in power between factions and result in different interpretations, learning, and outcomes for the organization (Levitt and March 1988). Overall, our findings highlight the need for a multi-level view of organizational learning (Kim 1993).

Our work also identifies potentially fruitful directions for future research on the effect of success and failure on individual learning. As noted by earlier research, prior experience may have a varying impact on both the effort and search strategy of the actor. This suggests a mediation model where a previous outcome leads to a subsequent effort decision followed by a search strategy and then a repetition of the activity. Each of these links is worth additional study, both in the laboratory (through controlled experiments) and in the field. Attribution theory suggests that individual failure may reduce effort in subsequent searches. Failure could potentially improve the search strategy, but not without effort. By studying this model in more detail, future work can not only gain additional insight into the micromechanisms explaining individual learning but also identify moderators that may help (or hurt) at each stage.

Finally, further work is needed to clarify how moderating variables affect how individuals internalize failure. We find that individuals with a greater number of prior successes are more able to learn from their failures than those with fewer successes, a result consistent with the findings of Kim et al. (2009) at the organizational level. Our effect may be a result of reduced self-threat, additional knowledge, or associative learning. In addition to exploring these mechanisms, future research could explore how factors of the task, such as difficulty (Siemsen 2008), uncertainty, or ambiguity, might affect an individual's learning from either success or failure.

Additionally, our moderation results suggest that a greater number of failures by others helps individuals learn from their own failures. Future work could examine the drivers behind this effect. It could be that this result is explained by how an individual views the opportunity provided by failure (e.g., to become a star by solving a difficult problem) or by whether greater failure helps create a culture where failure is seen as an opportunity to learn. Work examining the role of intra-group factors such as psychological safety on the propensity to learn from failure (Edmondson 1999) would also prove valuable. In psychologically safe teams, individuals are willing to take risks, as they know that it will not be held against them, and the possibility of failure is accepted within the team. By building a culture of psychological safety, organizations and teams alike can assure that members will be more willing and 
likely to take risks, but it is unclear whether such efforts can also increase members' self-reflection and willingness to learn from their failures. Additionally, future research could examine in what other ways managers might intervene to build cultures that can learn from failure. For example, the onboarding process for new workers, during which workers negotiate their identities and shape their expectations of the firm, could offer a key opportunity to accomplish such an objective (Cable, Gino and Staats 2012).

\subsection{Limitations}

Although our findings are robust to various empirical specifications, there are limitations that should be noted. First, we are able to track the detailed chronological experience of all individuals in the state of Massachusetts that completed the minimally invasive surgical procedure over a ten-year period of time. However, we do not have information on the first year of the rollout of the procedure. While our models are not biased in their estimation, future work with more data would be valuable. Second, while we can identify whether one success or failure occurred before another, we cannot know what information individuals actually observed among one another. Prior work at the organizational level suggests that organizations may under-sample failures and therefore draw incorrect conclusions (Denrell 2003). While our reported results are statistically valid, future work should explore what knowledge is known and shared under different conditions and also seek to identify the precise micro-mechanisms at work.

Third, we focus our attention on one particular performance outcome, the quality of the surgery. While this measure is commonly used in healthcare settings (e.g., Huckman and Pisano 2006; KC and Staats 2012), and is clearly an important one given the stakes involved, future work could explore the relationships studied here by using other outcome measures. For instance, using data from software projects, one could use time of project completion and delivery as compared to predetermined deadlines as the performance measure. Similarly, in service settings, one could use customer satisfaction as the outcome measure.

Fourth, the surgical process is not completed by only the surgeon; other individuals in the operating room provide assistance to her or him. However, the cardiothoracic surgeon is responsible for executing the critical surgical processes on the heart. As is the case in other healthcare studies, we have information about surgeons but not the rest of the surgery team (e.g., Novick and Stitt 1999; Reagans et al. 2005; Huckman and Pisano 2006). Given prior work noting that shared experience among team members can improve performance (Edmondson et al. 2003; Huckman, Staats and Upton 2009; Huckman and Staats 2011), an interesting future extension of this work would be to explore how familiarity among team members affects our reported results.

Fifth, prior work suggests that the effects from attribution theory are stronger in more individualistic cultures as compared to more collective cultures - for example, Western cultures as 
compared to Eastern cultures (Gilbert and Malone 1995). Future work should seek to explore how learning from failure or success operates in different cultures.

Sixth, in our setting we are able to clearly distinguish between failures (i.e., the patient dies after surgery) and successes (i.e., the patient survives). However, there are other sub-categories of success and failure that warrant further study. One of them is "near misses," defined as an experience that was almost a failure but ended up as a success. Prior research suggests that, as in the case of failures, organizations often fail to learn from near-misses (Dillon and Tinsley 2008). While our data does not provide us with information on near-misses, future research examining when and how individuals learn from near-misses in real-world settings and in healthcare in particular would be valuable. A second subcategory is that of expected rather than unexpected failures and successes. For instance, in a healthcare context, expected failure may result from a complicated case that went wrong, while unexpected failure may result from an easy case that went wrong. Examining the consequences for individual learning of both expected and unexpected failures (as well as successes) could be valuable. The mortality rate in our data is 3\%, a small number that limits our ability to split the sample to distinguish between expected and unexpected failures, and draw valid statistical inferences. It is possible that the effects of attribution theory would be heightened for an individual's own expected failure and weakened for unexpected failure. Future research also could investigate other contexts where expected and unexpected failures (or success) are equally likely. One such context is sports, where teams often have information about the competitors they play and can form expectations about their likelihood of winning. An additional, related question for further examination involves the probability of success versus failure. In our setting, success is more likely than failure. How might our results change if success was rare and failure was common (e.g., searching for a cure for cancer)?

A seventh limitation is related to individual differences across surgeons. While we have anonymous surgeon identifiers in our dataset in order to control for individual-level fixed effects, it is possible that specific individual differences among surgeons could provide further explanatory power in our regressions. We do not have such information, but future work could examine whether factors such as gender or educational background have differential effects for the relationships we investigated.

Finally, while we control for individual and hospital fixed effects as well as patient preoperative risk, we cannot rule out the possibility that there may be unobserved, time-varying heterogeneity in individual or organizational accident proneness or preoperative patient risk. Surgeons who operate in accident-prone environments or who treat more risky patients are likely to have more adverse outcomes, but (by attribution theory) are also more like to attribute their failure to their external circumstances. This kind of justification may mean that these surgeons learn less from failures than do surgeons who are less 
accident prone and who treat less risky patients. Because our data limitations preclude us from testing this possibility, we present it as an area for future research.

\subsection{Theoretical Contributions and Managerial Implications}

We make several theoretical contributions to research in operations management, organizational learning, and healthcare. First, as work grows increasingly fragmented - more specialized and divided into smaller tasks, the role of individuals in understanding organizational learning increases in importance (Argote and Miron-Spektor 2011; Malone et al. 2011; Clark, Huckman and Staats 2012; Staats and Gino 2012). By focusing on individuals, we gain a more nuanced understanding of how success and failure influence performance in organizations. Drawing on attribution theory, we hypothesize and find that individuals learn more from their own success than from their own failure rather than the opposite. Second, research on vicarious learning notes the challenges that may come from trying to learn from others (Hansen 1999; Bresman 2010). Our research contributes to this line of work by examining the sometimes beneficial and sometimes complicating factor of attributions. We find that the failure of others has a greater positive effect on individual performance than does others' successful experience. Third, we examine how one's own prior experience and the experience of others can alter the failure to learn from failure. Our results show that certain types of experience help to counteract individuals' errors of attribution and thus make them more open to learning from their failures. Together, our results advance our understanding of individual learning by drawing on research in psychology on attribution theory.

Our research has implications for healthcare and for organizations more generally. Recent studies suggest that, despite the increased focus on medical errors and investigation, hospitals are not getting safer (Landrigan et al. 2010). While we cannot draw a causal connection from our results to this finding, by improving individuals' ability to learn from prior experience, it may be possible to improve future outcomes. Given that performance in healthcare is quite literally a matter of life and death, it is important for individuals to learn from both their successes and failures. Existing inquiry boards and the potential for legal liability may complicate the ability of an individual to learn from his own failures. In particular, instead of focusing on how to learn from a mistake, an individual may have an increased incentive to explain away the mistake. While existing systems may help others learn from an individual's failure, it is necessary to design systems that help an individual learn from his own failure. As discussed by Edmondson (2011), for such systems to succeed, leaders must play a key role in helping individuals feel safe about admitting their responsibility for failure and learning from that failure. 


\section{Tables}

Table I

Patient Summary Statistics

\begin{tabular}{lccc}
\hline \hline Variable & Mean & Standard Deviation & Median \\
\hline Risk Adjusted Mortality & 0.0353 & 0.06625 & 0.0122 \\
Age & 67.53 & 11.16 & 69 \\
Gender (Female = 1) & 0.287 & 0.453 & 0 \\
Charlson Score & 0.909 & 1.034 & 1 \\
Cerebrovascular Disease & 0.0904 & 0.287 & 0 \\
COPD & 0.157 & 0.364 & 0 \\
Diabetes & 0.290 & 0.454 & 0 \\
Diabetes with Complications & 0.0517 & 0.221 & 0 \\
Chronic Renal Failure & 0.050 & 0.218 & 0 \\
Incidence of Myocardial & 0.292 & 0.454 & 0 \\
Infarction & & & 0 \\
PTCA & 0.0395 & 0.195 & 0 \\
\hline \hline
\end{tabular}

$\mathrm{N}=6516$ Patients

Table II

Effects of Cumulative Successes and Failures on Outcome

\begin{tabular}{lcc}
\hline \hline & $(1)$ & $(2)$ \\
\hline Individual Cumulative Failure & $0.1709(0.077) * *$ & $0.257(0.08) * * *$ \\
Individual Cumulative Success & $-0.00727(0.0036) * *$ & $-0.0108(0.005) * *$ \\
Others' Cumulative Failure & $-0.0354(0.0197) *$ & $-0.040(0.023)^{*}$ \\
Others' Cumulative Success & $-0.00019(0.00162)$ & $0.0012(0.0016)$ \\
Surgeon Fixed Effect & Yes & Yes \\
Hospital Fixed Effect & Yes & Yes \\
Time Fixed Effect (Month, Year) & Yes & No \\
Day of Week & Yes & Yes \\
Patient Race & Yes & Yes \\
Patient Age & Yes & Yes \\
Patient Gender & Yes & Yes \\
Charlson Score & Yes & Yes \\
Cerebrovascular Disease & Yes & Yes \\
COPD & Yes & Yes \\
Diabetes & Yes & Yes \\
Diabetes with Complications & Yes & Yes \\
Chronic Renal Failure & Yes & Yes \\
PTCA & Yes & Yes \\
Previous Myocardial Infarction & Yes & Yes \\
Length of Stay & Yes & Yes \\
Number of Vessels Bypassed & Yes & Yes \\
Likelihood Ratio (Pro $>$ ChiSq) & $<0.0001$ & $<0.0001$ \\
\hline \hline$N=6516$ Asymptotic standard errors clustered by surgeon in parentheses * 10\% Statistical Significance, **5\% & \\
& Statistical Significance, *** $1 \%$ Statistical Significance & \\
\hline
\end{tabular}


Table III

Interaction Effect of Cumulative Successes and Failures on Outcome

\begin{tabular}{|c|c|c|c|c|}
\hline & (1) & (2) & (3) & (4) \\
\hline Individual Cumulative & 0.521 & 0.458 & 0.524 & 0.707 \\
\hline Failure & $(0.099) * * *$ & $(0.139) * * *$ & $(0.166) * * *$ & $(0.159) * * *$ \\
\hline Individual Cumulative & 0.00097 & -0.00951 & -0.00931 & -0.0109 \\
\hline Success & $(0.00378)$ & $(0.00336)^{* * *}$ & $(0.003) * * *$ & $(0.00933)$ \\
\hline Others' Cumulative & -0.0263 & 0.014 & 0.022 & 0.013 \\
\hline Failure & $(0.022)$ & $(0.0223)$ & $(0.0197)$ & $(0.0288)$ \\
\hline Others' Cumulative & -0.0076 & -0.00015 & 0.00254 & -0.00216 \\
\hline Success & $(0.00163)$ & $(0.00017)$ & $(0.00179)$ & $(0.00299)$ \\
\hline Individual Cum. Success & -0.00189 & - & - & -0.0014 \\
\hline x Individual Cum. Failure & $(0.0003) * * *$ & & & $(0.0006) * *$ \\
\hline Individual Cum. Failure $\mathrm{x}$ & - & -0.00699 & - & -0.00618 \\
\hline Others' Cum. Failure & & $(0.00226)^{* * *}$ & & $(0.0034) *$ \\
\hline Individual Cum. Success & - & - & -0.000006 & 0.000013 \\
\hline x Others' Cum. Success & & & $(0.000009)$ & $(0.000015)$ \\
\hline Surgeon Fixed Effect & Yes & Yes & Yes & Yes \\
\hline Hospital Fixed Effect & Yes & Yes & Yes & Yes \\
\hline $\begin{array}{l}\text { Time Fixed Effect } \\
\text { (Month, Year) }\end{array}$ & Yes & Yes & Yes & Yes \\
\hline Day of Week & Yes & Yes & Yes & Yes \\
\hline Patient Race & Yes & Yes & Yes & Yes \\
\hline Patient Age & Yes & Yes & Yes & Yes \\
\hline Patient Gender & Yes & Yes & Yes & Yes \\
\hline Charlson Score & Yes & Yes & Yes & Yes \\
\hline Cerebrovascular Disease & Yes & Yes & Yes & Yes \\
\hline COPD & Yes & Yes & Yes & Yes \\
\hline Diabetes & Yes & Yes & Yes & Yes \\
\hline Diabetes with & Yes & Yes & Yes & Yes \\
\hline Complications & & & & \\
\hline Chronic Renal Failure & Yes & Yes & Yes & Yes \\
\hline PTCA & Yes & Yes & Yes & Yes \\
\hline $\begin{array}{l}\text { Previous Myocardial } \\
\text { Infarction }\end{array}$ & Yes & Yes & Yes & Yes \\
\hline Length of Stay & Yes & Yes & Yes & Yes \\
\hline Number of Vessels & Yes & Yes & Yes & Yes \\
\hline Bypassed & & & & \\
\hline $\begin{array}{l}\text { Likelihood Ratio (Pro > } \\
\text { ChiSq) }\end{array}$ & $<0.0001$ & $<0.0001$ & $<0.0001$ & $<0.0001$ \\
\hline
\end{tabular}

$N=6516$ Asymptotic standard errors clustered by surgeon in parentheses * 10\% Statistical Significance, ** $5 \%$ Statistical Significance, *** 1 \% Statistical Significance 
Table A-I

Effects of Cumulative Volume on Outcome

\begin{tabular}{lcc}
\hline \hline & $(1)$ & $(2)$ \\
\hline Individual Cumulative Volume & $0.00217(0.0012) *$ & $0.00187(0.001)^{*}$ \\
Surgeon Fixed Effect & Yes & Yes \\
Hospital Fixed Effect & Yes & Yes \\
Time Fixed Effect (Month, Year) & Yes & No \\
Day of Week & Yes & Yes \\
Patient Race & Yes & Yes \\
Patient Age & Yes & Yes \\
Patient Gender & Yes & Yes \\
Charlson Score & Yes & Yes \\
Cerebrovascular Disease & Yes & Yes \\
COPD & Yes & Yes \\
Diabetes & Yes & Yes \\
Diabetes with Complications & Yes & Yes \\
Chronic Renal Failure & Yes & Yes \\
PTCA & Yes & Yes \\
Previous Myocardial Infarction & Yes & Yes \\
Length of Stay & Yes & Yes \\
Number of Vessels Bypassed & Yes & Yes \\
Likelihood Ratio (Pro $>$ ChiSq) & $<0.0001$ & $<0.0001$ \\
\hline Statistical Significance, *** $1 \%$ Statistical Significance & & \\
& &
\end{tabular}


Table A-II

Robustness Test

\begin{tabular}{lc}
\hline & $(1)$ \\
\hline Individual Cumulative Failure & $0.903(0.163) * * *$ \\
Individual Cumulative Success & $-0.0314(0.009) * * *$ \\
Others' Cumulative Failure & $-0.0384(0.020)^{*}$ \\
Others' Cumulative Success & $0.00028(0.0018)$ \\
Individual Cum. Failure Sq. & $-0.0314(0.0087) * * *$ \\
Individual Cum. Success Sq. & $0.000048(0.0000) * * *$ \\
Surgeon Fixed Effect & Yes \\
Hospital Fixed Effect & Yes \\
Time Fixed Effect (Month, Year) & Yes \\
Day of Week & Yes \\
Patient Race & Yes \\
Patient Age & Yes \\
Patient Gender & Yes \\
Charlson Score & Yes \\
Cerebrovascular Disease & Yes \\
COPD & Yes \\
Diabetes & Yes \\
Diabetes with Complications & Yes \\
Chronic Renal Failure & Yes \\
PTCA & Yes \\
Previous Myocardial Infarction & Yes \\
Length of Stay & Yes \\
Number of Vessels Bypassed & Yes \\
Likelihood Ratio (Pro $>$ ChiSq) & $<0.0001$ \\
\hline \hline totic standard errors clustered by surgeon in parentheses * $10 \%$ Statistical Significance, ** $5 \%$ \\
ificance, *** $\%$ Statistical Significance
\end{tabular}




\section{References}

AHA (2008). American Hospital Association Annual Survey of Hospitals, American Hospital Association.

Argote, L. (1999). Organizational Learning: Creating, Retaining, and Transferring Knowledge. Boston, Kluwer Academic.

Argote, L., S. L. Beckman and D. Epple (1990). "The persistence and transfer of learning in industrial settings." Management Sci. 36(2): 140-154.

Argote, L. and P. Ingram (2000). "Knowledge transfer: A basis for competitive advantage in firms." Organ. Behav. Human Decision Processes 82(1): 150-169.

Argote, L. and E. Miron-Spektor (2011). "Organizational learning: From experience to knowledge." Organ. Sci. 22(5): 1123-1137.

Argyris, C. and D. A. Schön (1978). Organizational learning. Reading, Mass., Addison-Wesley Pub. Co.

Audia, P. G. and J. A. Goncalo (2007). "Past success and creativity over time: A study of inventors in the hard disk drive industry." Management Sci. 53(1): 1-15.

Bandura, A. (1977). "Self-efficacy: Toward a unifying theory of behavioral change." Psych. Rev. 84(2): 191-215.

Baum, J. A. C. and K. B. Dahlin (2007). "Aspiration performance and railroads' patterns of learning from train wrecks and crashes." Organ. Sci. 18(3): 368-385.

Baumeister, R. F., E. Bratslavsky, C. Finkenauer and K. D. Vohs (2001). "Bad is stronger than good." Review of General Psychology 5(4): 323-370.

Blume, A. and A. M. Franco (2007). "Decentralized learning from failure." Journal of Economic Theory 133(1): 504-523.

Bohn, R. E. (2005). "From art to science in manufacturing: The evolution of technological knowledge." Foundations and Trends in Technology, Information and Operations Management 1(2): 129-212.

Bohn, R. E. and M. A. Lapré (2011). Accelerated learning by experimentation. Learning Curves: Theory, Models, and Applications. M. Y. Jaber. Boca Raton, FL, CRC Press, Taylor and Francis: 191209.

Bresman, H. (2010). "External learning activities and team performance: A multimethod field study." Organ. Sci. 21(1): 81-96.

Cable, D. M., F. Gino and B. R. Staats (2012). "Breaking them in or revealing their best? Reframing socialization around newcomer self expression." HBS Working Paper: Boston.

Campbell, W. and C. Sedikides (1999). "Self-threat magnifies the selfserving bias: A meta-analytic integration." Review of General Psychology 3: 23-43. 
Cannon, M. D. and A. C. Edmondson (2005). "Failing to learn and learning to fail (intelligently): How great organizations put failure to work to innovate and improve." Long Range Planning 38(3): 299-319.

Chan, T., J. Li and J. L. Pierce (2012). "Learning from Peers." Washington University in St. Louis Working Paper.

Chuang, Y.-T. and J. A. C. Baum (2003). "It's all in the name: Failure-induced learning by multiunit chains." Administrative Sci. Q. 48(1): 33-59.

Clark, J. R., R. S. Huckman and B. R. Staats (2012). Customer specificity and learning: Evidence from outsourced radiological services. HBS Working Paper. Boston.

Crossan, M. M., H. W. Lane and R. E. White (1999). "An organizational learning framework: From intuition to institution." Acad. Management Rev. 24(3): 522-537.

Cyert, R. M. and J. G. March (1963). A Behavioral Theory of the Firm. Englewood Cliffs, N.J., PrenticeHall.

Daft, R. L. and K. E. Weick (1984). "Toward a model of organizations as interpretation systems." Acad. Management Rev. 9(2): 284-295.

Darr, E. D., L. Argote and D. Epple (1995). "The acquisition, transfer, and depreciation of knowledge in service organizations: Productivity in franchises." Management Sci. 41(11): 1750-1762.

Denrell, J. (2003). "Vicarious learning, undersampling of failure, and the myths of management." Organ. Sci. 14(3): 227-243.

Dillon, R. L. and C. H. Tinsley (2008). "How near-misses influence decision making under risk: A missed opportunity for learning." Management Sci. 54(8): 1425-1440.

Drucker, P. F. (1999). "Knowledge-worker productivity: The biggest challenge." California Management Review 41(2): 79-94.

Dunning, D. (1999). "A newer look: Motivated social cognition and the schematic representation of social concepts." Psychological Inquiry 10: 1-11.

Edmondson, A. (1999). "Psychological safety and learning behavior in work teams." Administrative Sci. Q. 44(2): 350-383.

Edmondson, A. C. (2002). "The local and variegated nature of learning in organizations: A group-level perspective." Organ. Sci. 13(2): 128.

Edmondson, A. C. (2011). "Strategies for learning from failure." Harvard Business Rev. 89(4): 48-55.

Edmondson, A. C., A. Winslow, R. Bohmer and G. P. Pisano (2003). "Learning how and learning what: Effects of tacit and codified knowledge on performance improvement following technology adoption." Decision Sci. 34(2): 197-223.

Fleming, L. and O. Sorenson (2004). "Science as a map in technological search." Strategic Management J. 25(8-9): 909-928. 
Friedrich, G. J., J. Bonatti and O. E. Dapunt (1997). "Preliminary experience with minimally invasive coronary-artery bypass surgery combined with coronary angioplasty." N. Engl. J. Med. 336(20): 1454-1455.

Gardner, D. (2001). CardioThoracic Systems. Harvard Business School Case 9-899-281. Boston.

Gavetti, G., D. Levinthal and W. Ocasio (2007). "Perspective--Neo-Carnegie: The Carnegie School's past, present, and reconstructing for the future." Organ. Sci. 18(3): 523-536.

Gilbert, D. T. and P. S. Malone (1995). "The correspondence bias." Psych. Bull. 117(1): 21-38.

Gino, F., L. Argote, E. Miron-Spektor and G. Todorova (2010). "First, get your feet wet: The effects of learning from direct and indirect experience on team creativity." Organ. Behav. Human Decision Processes 111(2): 102-115.

Gino, F. and G. P. Pisano (2011). "Why leaders don't learn from success." Harvard Business Rev. 89(4): 68-74.

Greve, H. R. (1998). "Performance, aspirations, and risky organizational change." Administrative Sci. Q. 43(1): 58-86.

Hansen, M. T. (1999). "The Search-Transfer Problem: The role of weak ties in sharing knowledge across organization subunits." Administrative Sci. Q. 44(1): 82-111.

Haunschild, P. R. and M. Rhee (2004). "The role of volition in organizational learning: The case of automotive product recalls." Management Sci. 50(11): 1545-1560.

Haunschild, P. R. and B. N. Sullivan (2002). "Learning from complexity: Effects of prior accidents and incidents on airlines' learning." Administrative Sci. Q. 47(4): 609.

Heider, F. (1958). The Psychology of Interpersonal Relations. New York, Wiley.

Higgins, T. L., F. G. Estafanous, F. D. Loop, G. J. Beck, J. M. Blum and L. Paranandi (1992). "Stratification of morbidity and mortality outcome by preoperative risk factors in coronary artery bypass patients." JAMA 267(17): 2344-2348.

Huber, G. P. (1991). "Organizational learning: The contributing processes and the literatures." Organ. Sci. 2(1): 88-115.

Huckman, R. S. (2003). "The utilization of competing technologies within the firm: Evidence from cardiac procedures." Management Sci. 49(5): 599-617.

Huckman, R. S. and G. P. Pisano (2006). "The firm specificity of individual performance: Evidence from cardiac surgery." Management Sci. 52(4): 473-488.

Huckman, R. S. and B. R. Staats (2011). "Fluid tasks and fluid teams: The impact of diversity in experience and team familiarity on team performance." Manufacturing Service Oper. Management 13(3): 310-328.

Huckman, R. S., B. R. Staats and D. M. Upton (2009). "Team familiarity, role experience, and performance: Evidence from Indian software services." Management Sci. 55(1): 85-100. 
Ingram, P. and J. A. C. Baum (1997). "Opportunity and constraint: Organizations' learning from the operating and competitive experience of industries." Strategic Management J. 18(Summer): 7598.

Ingram, P. and P. W. Roberts (2000). "Friendships among competitors in the Sydney hotel industry." American Journal of Sociology 106(2): 387-423.

Jones, E. E. and K. E. Davis (1965). From acts to dispositions: The attribution process in person perception. Advances in Experimental Social Psychology. L. Berkowitz. San Diego, CA, Academic Press. 2: 219-266.

Jones, E. E. and V. A. Harris (1967). "The attribution of attitudes." J. of Experimental Soc. Psych. 3(1): 124.

Katz, D. and R. L. Kahn (1966). The Social Psychology of Organizations. New York, Wiley.

KC, D. and B. R. Staats (Forthcoming). "Accumulating a portfolio of experience: The effect of focal and related experience on surgeon performance." Manufacturing Service Oper. Management.

KC, D. and C. Terwiesch (2009). "Impact of workload on service time and patient safety: An econometric analysis of hospital operations." Management Sci. 55(9): 1486-1498.

KC, D., C. Terwiesch and J. Horak (2009). "Cardiothoracic surgery risk stratification for intra-hospital decision making and inter-hospital quality comparisons." Wharton School Working Paper.

Kelley, H. H. (1967). Attribution theory in social psychology. Nebraska Symposium on Motivation. D. Levine. Lincoln, University of Nebraska Press. 15: 192-238.

Kim, D. H. (1993). "The link between individual learning and organizational learning." Sloan Management Review 35(1): 37-50.

Kim, J.-Y., J.-Y. Kim and A. S. Miner (2009). "Organizational learning from extreme performance experience: The impact of success and recovery experience." Organ. Sci. 20(6): 958-978.

Kim, J.-Y. J. and A. S. Miner (2007). "Vicarious learning from the failures and near-failures of others: Evidence from the U.S. commercial banking industry." Academy Manage. J. 50(3): 687-714.

Landrigan, C. P., G. J. Parry, C. B. Bones, A. D. Hackbarth, D. A. Goldmann and P. J. Sharek (2010). "Temporal trends in rates of patient harm resulting from medical care." N. Engl. J. Med. 363(22): 2124-2134.

Lant, T. K. (1992). "Aspiration Level Adaptation: An Empirical Exploration." Management Sci. 38(5): 623-644.

Lapré, M. A. (2011). Inside the learning curve: Opening the black box of the learning curve. Learning Curves: Theory, Models, and Applications. M. Y. Jaber. Boca Raton, FL, CRC Press, Taylor and Francis: 23-35.

Lapré, M. A., A. S. Mukherjee and L. N. V. Wassenhove (2000). "Behind the learning curve: Linking learning activities to waste reduction." Management Sci. 46(5): 597-611. 
Lapré, M. A. and I. M. Nembhard (2010). "Inside the organizational learning curve: Understanding the organizational learning process." Foundations and Trends in Technology, Information and Operations Management 4(1): 1-103.

Lapré, M. A. and N. Tsikriktsis (2006). "Organizational learning curves for customer dissatisfaction: Heterogeneity across airlines." Management Sci. 52(3): 352-366.

Lapré, M. A. and L. N. van Wassenhove (2001). "Creating and transferring knowledge for productivity improvement in factories." Management Sci. 47(10): 1311-1325.

Levitt, B. and J. G. March (1988). "Organizational learning." Annual Review of Sociology 14: 319-340.

Levy, F. K. (1965). "Adaptation in the production process." Management Sci. 11(6): B136-B154.

Lewin, K. (1931). "The conflict between Aristotelian and Galileian modes of thought in contemporary psychology." Journal of General Psychology 5: 141-177.

Li, G. and S. Rajagopalan (1997). "The impact of quality on learning." J. of Operations Management 15(3): 181-191.

Locke, E. A. and J. F. Bryan (1967). "Performance goals as determinants of level of performance and boredom." J. Appl. Psych. 51(2): 120-130.

Locke, E. A., K. N. Shaw, L. M. Saari and G. P. Latham (1981). "Goal setting and task performance: 1969-1980." Psych. Bull. 90(1): 125-152.

Madsen, P. M. and V. Desai (2010). "Failing to learn? The effects of failure and success on organizational learning in the global orbital launch vehicle industry." Academy Manage. J. 53(3): 451-476.

Malone, T. W., R. J. Laubacher and T. Johns (2011). "The age of hyperspecialization." Harvard Business Rev. 89(7/8): 56-65.

March, J. G. (1991). "Exploration and exploitation in organizational learning." Organ. Sci. 2(1): 71-87.

March, J. G. and H. A. Simon (1993). Organizations. Cambridge, MA, Blackwell.

Miner, A. S. and P. R. Haunschild (1995). Population level learning. Research in Organizational Behavior. L. L. Cummings and B. M. Staw. Greenwich, CT, JAI Press: 115-166.

Moore, D. A. and P. J. Healy (2008). "The trouble with overconfidence." Psych. Rev. 115(2): 502-517.

Moore, D. A., S. A. Swift, Z. Sharek and F. Gino (2010). "Correspondence bias in performance evaluation: Why grade inflation works." Personality Soc. Psych. Bull. 36(6): 843-852.

Morris, M. W. and P. C. Moore (2000). "The lessons we (don't) learn: Counterfactual thinking and organizational accountability after a close call." Administrative Sci. Q. 45(4): 737-765.

Narayanan, S., S. Balasubramanian and J. M. Swaminathan (2009). "A matter of balance: Specialization, task variety, and individual learning in a software maintenance environment." Management Sci. 55(11): 1861-1876. 
Nashef, S. A., F. Roques, B. G. Hammill, E. D. Peterson, P. Michel, F. L. Grover, R. K. Wyse and T. B. Ferguson (2002). "Validation of European System for Cardiac Operative Risk Evaluation (EuroSCORE) in North American cardiac surgery " Eur. J. Cardiothoracic Surgery 22: 101-105.

Newell, A. and P. Rosenbloom (1981). Mechanisms of skill acquisition \& the power law of practice. Cognitive Skills \& Their Acquisition. J. Anderson. Hillsdale, NJ, Erlbaum: 1-55.

Novick, R. J. and L. W. Stitt (1999). "The learning curve of an academic cardiac surgeon: Use of the CUSUM Method." Journal of Cardiac Surgery 14(5): 312-320.

Parsonnet, V., D. Dean and A. D. Bernstein (1989). "A method of uniform stratification of risk for evaluating the results of surgery in acquired adult heart disease." Circulation 79(6 Pt 2): I3-12.

Piaget, J. (1963). The Psychology of Intelligence. New York, Routledge.

Pisano, G. P., R. M. J. Bohmer and A. C. Edmondson (2001). "Organizational differences in rates of learning: Evidence from the adoption of minimally invasive cardiac surgery." Management Sci. 47(6): 752-768.

Puskas, J. D., C. E. Wright, R. S. Ronson, W. M. BrownIII, J. P. Gott and R. A. Guyton (1998). "Offpump multivessel coronary bypass via sternotomy is safe and effective." The Annals of Thoracic Surgery 66(3): 1068-1072.

Reagans, R., L. Argote and D. Brooks (2005). "Individual experience and experience working together: Predicting learning rates from knowing who knows what and knowing how to work together." Management Sci. 51(6): 869-881.

Roach, G. W., M. Kanchuger, C. M. Mangano, M. Newman, N. Nussmeier, R. Wolman, A. Aggarwal, K. Marschall, S. H. Graham, C. Ley, G. Ozanne, D. T. Mangano, A. Herskowitz, V. Katseva and R. Sears (1996). "Adverse Cerebral Outcomes after Coronary Bypass Surgery." N. Engl. J. Med. 335(25): 1857-1864.

Ross, L. (1977). The intuitive psychologist and his shortcomings. Advances in Experimental Social Psychology. L. Berkowitz. San Diego, CA, Academic Press. 10: 173-220.

Ross, L., T. M. Amabile and J. L. Steinmetz (1977). "Social roles, social control, and biases in socialperception processes." J. Personality Soc. Psych. 35(485-494).

Ross, L. and E. Nisbett (1991). The Person and the Situation: Perspectives of Social Psychology. New York, McGraw-Hill.

Sedikides, C. (1993). "Assessment, enhancement, and verification determinants of the self-evaluation process." J. Personality Soc. Psych. 65: 317-338.

Siemsen, E. (2008). "The hidden perils of career concerns in R\&D organizations." Management Sci. 54(5): 863-877.

Sitkin, S. B. (1992). Learning through failure: The strategy of small losses. Research in Organizational Behavior. L. L. Cummings and B. M. Staw. Greenwich, CT, JAI Press. 14. 
Staats, B. R. (2012). "Unpacking team familiarity: The effect of geographic location and hierarchical role." Production and Operations Management. 21(3): 619-635.

Staats, B. R. and F. Gino (2012). "Specialization and variety in repetitive tasks: Evidence from a Japanese bank." Management Sci. 58(6): 1141-1159.

Stata, R. (1989). "Organizational learning -- The key to management innovation." Sloan Management Review 30(3): 63-74.

Staw, B. M. (1981). "The escalation of commitment to a course of action." Acad. Management Rev. 6(4): 577-587.

Sternberg, R. J. (2003). Cognitive Psychology. Belmont, CA, Thomson/Wadsworth.

Taylor, S. E. and J. D. Brown (1988). "Illusion and well-being: A social psychological perspective on mental health." Psych. Bull. 103: 193-210.

Taylor, S. E. and S. T. Fiske (1978). Salience, attention and attribution: Top of the head phenomena. Advances in Experimental Social Psychology. L. Berkowitz. New York, Academic Press. 11: 249-288.

Teece, D. J., G. Pisano and A. Shuen (1997). "Dynamic capabilities and strategic management." Strategic Management J. 18(7): 509-533.

Weick, K. E. (1984). "Small wins: Redefining the scale of social problems." American Psychologist 39(1): 40-49.

Weiner, B. (1974). Achievement Motivation and Attribution Theory. Morristown, NJ, General Learning Press.

Weiner, B. (1979). "A theory of motivation for some classroom experiences." Journal of Educational Psychology 72: 676-681.

Weiner, B. (1995). Judgments of Responsibility: A Foundation for a Theory of Social Conduct. New York, Guildford.

Weiner, B. (2001). Intrapersonal and interpersonal theories of motivation from an attribution perspective. Student Motivation, The Springer Series on Human Exceptionality. F. Salili, C. Chiu and Y. Hong, Springer US: 17-30.

Wong, P. T. P. and B. Weiner (1981). "When people ask "Why" questions, and the heuristics of attributional search." J. Personality Soc. Psych. 40(4): 650-663.

Wood, R. and A. Bandura (1989). "Social cognitive theory of organizational management." Acad. Management Rev. 14(3): 361-384. 